\title{
Activity of vancomycin, teicoplanin and cephalosporins against penicillin-susceptible and penicillin-intermediate Streptococcus pneumoniae
}

\author{
Vivian G LoO mD, Jocelyne Lavallée Rt, Diane McAlear RT, Hugh G Robson mD
}

VG Loo, J LAVAlLÉE, D McAlear, HG RoBson. Activity of vancomycin, teicoplanin and cephalosporins against penicillin-susceptible and penicillin-intermediate Streptococcus pneumoniae. Can J Infect Dis 1995;6(2):8387.

ОвJеCtIVE: To report in vitro susceptibilities of penicillin-susceptible and penicillin-intermediate Streptococcus pneumoniae isolates to cephalosporins, vancomycin and teicoplanin.

DESIGN: Minimal inhibitory concentrations (MIC) were determined according to National Committee for Clinical Laboratory Standards guidelines for 17 penicillin-susceptible isolates (MIC $0.06 \mathrm{mg} / \mathrm{L}$ or less) and 16 isolates showing intermediate susceptibility to penicillin (MIC 0.12 to $1.0 \mathrm{mg} / \mathrm{L}$ ).

Setting: Tertiary care university centre.

MAIN RESULTS: Comparison of the MIC90 values with those of other antibiotics tested demonstrated that ceftriaxone, cefotaxime and teicoplanin were the most active agents against penicillin-susceptible strains. However, teicoplanin had the lowest MIC and was superior to other agents against strains with intermediate penicillin susceptibility. The MIcs of al cephalosporins increased in concordance with the MIC of penicillin.

CONCLUSION: Isolates demonstrating intermediate susceptibility or resistance to penicillin should be routinely evaluated for susceptibility to clinically important cephalosporins. (Pour résumé, voir page 84)

Key Words: Cephalosporins, Resistance, Streptococcus pneumoniae

Department of Microbiology, Royal Victoria Hospital, and Departments of Medicine and of Microbiology and Immunology, McGill University, Montreal, Quebec

Correspondence and reprints: Dr Vivian G Loo, Department of Microbiology, Royal Victoria Hospital, 687 Pine Avenue West, Room L5.06, Montreal, Quebec H3A 1A1. Telephone (514) 842-1231, ext 4559, Fax (514) 844-7526

Received for publication August 17, 1994. Accepted December 2, 1994 


\title{
Activité de la vancomycine, de la téicoplanine et des céphalosporines contre les Streptococcus pneumoniae sensibles à la pénicilline et modérément résistants à la pénicilline
}

\begin{abstract}
OBJectifs : Étudier la sensibilité in vitro d'isolats de Streptococcus pneumoniae sensibles à la pénicilline et modérément résistants à la pénicilline, à l'égard des céphalosporines, de la vancomycine et de la téicoplanine.

ModĖLE : Les concentrations minimales in vitro (CMI) ont été mesurées conformément aux directives du National Committee for Clinical Laboratory Standards à l'égard de 17 isolats sensibles à la pénicilline (CMI $0,06 \mathrm{mg} / \mathrm{L}$ ou moins) et de 16 isolats manifestant une sensibilité intermédiaire à la pénicilline (CMI 0,12 à 1,0 mg/L).

ConTEXTE : Centre hospitalier de soins tertiaires.

Principaux RÉsultats : La comparaison des valeurs de CMI 90 à celles d'autres antibiotiques testés a démontré que le ceftriaxone, le céfotaxime et la téicoplanine étaient les agents les plus efficaces contre les souches sensibles à la pénicilline. Toutefois, la téicoplanine a présenté la CMI la plus basse et s'est révélée supérieure aux autres agents contre les souches qui manifestaient une sensibilité intermédiaire. Les CMI de toutes les céphalosporines ont augmenté proportionnellement avec la cMı de la pénicilline.

ConcLusion : Les isolats qui manifestent une sensibilité intermédiaire ou une résistance à la pénicilline doivent être évalués d'office à l'égard de la susceptibilité aux céphalosporines d'usage courant.
\end{abstract}

$S$ TREPTOCOCCUS PNEUMONIAE IS A LEADING CAUSE OF UPper and lower respiratory tract infections. For many years, penicillin has remained the drug of choice for clinical disease (1). Since 1967, however, there have been increasing reports of penicillin resistance worldwide, especially in Spain and South Africa $(1,2)$. In the United States, the overall incidence of $S$ pneumoniae with intermediate susceptibility and resistance to penicillin is approximately $15 \%$, although there is great geographical variability (3). In comparison, Canada has reported incidence rates of intermediate penicillin susceptibility ranging from 1.3 to $4.6 \%$ (4-6). Indeed, there have been only rare isolated reports of truly penicillin-resistant $S$ pneumoniae from Canada (7).

Antibiotics such as cephalosporins and vancomycin serve as alternative therapeutic agents in infections with pneumococcal isolates intermediate or resistant to penicillin. Thirdgeneration cephalosporins such as cefotaxime and ceftriaxone have been considered antibiotics of choice for the treatment of meningitis due to $S$ pneumoniae because of their superior pharmacokinetic properties and their ability to penetrate into the cerebrospinal fluid (CSF) $(8,9)$. However, patients with meningitis caused by penicillin-resistant or penicillin-intermediate $S$ pneumoniae strains in which cephalosporin therapy failed have recently been described in the United States $(10,11)$. Pneumococcal isolates with minimal inhibitory concentrations (MICs) of $2 \mathrm{mg} / \mathrm{L}$ or greater to cefotaxime have also been reported from Hungary and states such as Kentucky and Tennessee $(12,13)$. The emergence of pneumococcal resistance to cephalosporins in Canada has not been examined. In this study, we report the susceptibility pattern of 17 penicillin-susceptible isolates and 16 penicillinintermediate isolates to penicillin, cefazolin, cefuroxime, cefixime, cefotaxime, ceftazidime, ceftriaxone, vancomycin and teicoplanin.

\section{MATERIALS AND METHODS}

$S$ pneumoniae strains were selected from the culture collection at the authors' institution of clinical isolates that were acquired from November 1987 to July 1993. Seventeen penicillin-susceptible isolates (MIC $0.06 \mathrm{mg} / \mathrm{L}$ or less) and 16 penicillin-intermediate isolates (MIC 0.12 to $1.0 \mathrm{mg} / \mathrm{L}$ ) were used in the study. Strains were obtained from blood (54\%), sputum $(36 \%)$ and bronchial washings (10\%). Each strain was isolated from a different patient. All isolates were identified as $S$ pneumoniae based on colony morphology, Gram stain, lack of catalase production, susceptibility to ethylhydrocuprein and bile solubility (14). Serotyping was performed by the Quellung method with 46 type or group pneumococcal antisera (Statens Seruminstitut, Copenhagen, Denmark). Reference strains used in this study for susceptibility testing were Enterococcus faecalis ATCC 29212 and Staphylococcus aureus ATCC 29213. Two additional strains of $S$ pneumoniae for which the MICs were previously reported were kindly provided by the Department of Microbiology, Hôpital Saint-Luc, Montréal, Québec.

All isolates were frozen at $-70^{\circ} \mathrm{C}$, thawed, subcultured onto Columbia agar containing $5 \%$ sheep's blood (Woodlyn Laboratories), and incubated at 35ÉC in 5\% carbon dioxide for $24 \mathrm{~h}$ preceding susceptibility testing. A suspension of growth was prepared in Mueller-Hinton broth (Woodlyn Laboratories) and adjusted to equal the turbidity of a $0.5 \mathrm{McFar}$ land standard. The standardized inoculum was diluted in sterile Mueller-Hinton broth to give a final concentration of approximately $5 \times 10^{5}$ colony forming units $/ \mathrm{mL}$. Tests were performed in duplicate by using the broth microdilution method as described in National Committee for Clinical Laboratory Standards (NCCLS) standard M7-A3 (15).

The antimicrobial agents tested were penicillin (Ayerst Laboratories), cefazolin (SmithKline Beecham), cefuroxime sodium, ceftazidime (Glaxo Canada Inc), cefixime (LederleCyanamid Canada Inc), cefotaxime (Hoechst-Roussel Canada Inc), ceftriaxone (Hoffman-LaRoche Limited), vancomycin (Eli Lilly Canada Inc) and teicoplanin (Merrell Dow Pharmaceuticals Inc). Agents were supplied as laboratory powders of known potency and stock solutions were made as recommended by the manufacturers. MICs were interpreted 
as susceptible, intermediate or resistant in accordance with the guidelines of the NCCLS for $S$ pneumoniae (15).

\section{RESULTS}

Susceptibility test results with $S$ pneumoniae isolates demonstrating intermediate susceptibility and full susceptibility to penicillin are contrasted in Table 1. Although the culture collection used dates back to November 1987, isolates with ceftriaxone and cefotaxime MICs of 0.25 to $1.0 \mathrm{mg} / \mathrm{L}$ became prevalent only after April 1991. The MIC90 of penicillin was $0.01 \mathrm{mg} / \mathrm{L}$ against penicillin-susceptible strains and $1.0 \mathrm{mg} / \mathrm{L}$ against penicillin-intermediate strains. Comparison of MIC90s obtained with the other antibiotics tested demonstrates that ceftriaxone, cefotaxime and teicoplanin were the most active agents against penicillin-susceptible strains. However, against penicillin-intermediate strains, teicoplanin, with the lowest MIC, was superior to other agents. The MICs of all cephalosporins increased in concordance with the MIC of penicillin. Ceftriaxone and cefotaxime were the most active of the cephalosporins, and had lower Mics than ceftazidime, cefixime and cefuroxime. Isolates were uniformly susceptible to both vancomycin and teicoplanin. Six isolates were resistant to cefuroxime (MIC $2 \mathrm{mg} / \mathrm{L}$ or greater); three isolates showed intermediate susceptibility to cefotaxime (MIC 0.5 to $1.0 \mathrm{mg} / \mathrm{L}$ ); and one isolate was intermediately susceptible to ceftriaxone (MIC $0.5 \mathrm{mg} / \mathrm{L}$ ). None were fully resistant to cefotaxime or to ceftriaxone. Of the three isolates that demonstrated intermediate susceptibility to cefotaxime, two belonged to serogroup 9 and the other to serogroup 23. Of the six cefuroximeresistant strains, four were associated with serogroup 23 and the other two with serogroup 9.

MIC tests performed in duplicate were approximately $95 \%$ concordant. In the cases of discordance, there was only one $\log _{2}$ difference and the higher MIC was recorded. Discordance did not occur in the strains with cephalosporin resistance.

\section{DISCUSSION}

Third-generation cephalosporins are commonly recommended for therapy of pneumococcal meningitis caused by isolates with intermediate penicillin susceptibility or penicillin resistance (9). To achieve sterilization of the CSF, experimental animal models have illustrated that antibiotic concentrations in the CSF should be at least eight- to 10-fold higher than the minimal bactericidal concentration of the infecting organism (8). Ceftriaxone or cefotaxime concentrations in the CSF of human subjects with meningitis are usually in the range of 3 to $7 \mathrm{mg} / \mathrm{L}$ with recommended dosages (8). Hence, clinical failure can be anticipated in cases of meningitis caused by isolates with MICs to cefotaxime and ceftriaxone of $0.5 \mathrm{mg} / \mathrm{L}$ or greater. Thus, NCCLS has recommended that $S$ pneumoniae isolates with cefotaxime, ceftriaxone and cefuroxime MICs in the 'intermediate' category should be considered to be resistant to these antibiotics and other beta-lactam antibiotics in patients with meningitis (15). Of the cephalosporins tested, ceftazidime had the highest MICs against penicillin-intermediate strains and they should not be used in clinical cases of meningitis with such isolates.
TABLE 1

In vitro susceptibility of 17 penicillin-susceptible and 16 penicillin-intermediate strains of Streptococcus pneumoniae

\begin{tabular}{|c|c|c|c|}
\hline \multirow{2}{*}{$\begin{array}{l}\text { Antimicrobial } \\
\text { agent }\end{array}$} & \multicolumn{3}{|c|}{ MIC (mg/L) } \\
\hline & Range & $\mathrm{MIC}_{50}$ & $\mathrm{MIC}_{90}$ \\
\hline \multicolumn{4}{|l|}{ Penicillin } \\
\hline Susceptible & $\leq 0.007-0.06$ & $\leq 0.007$ & 0.01 \\
\hline Intermediate & $0.12-1.0$ & 0.25 & 1.0 \\
\hline \multicolumn{4}{|l|}{ Cefazolin } \\
\hline Pen-S & $0.01-0.12$ & 0.06 & 0.06 \\
\hline Pen-I & $0.06-2.0$ & 0.50 & 1.0 \\
\hline \multicolumn{4}{|l|}{ Cefuroxime } \\
\hline Pen-S & $\leq 0.007-0.25$ & 0.01 & 0.03 \\
\hline Pen-I & $0.01-4.0$ & 0.50 & 2.0 \\
\hline \multicolumn{4}{|l|}{ Cefixime } \\
\hline Pen-S & $0.06-0.12$ & 0.12 & 0.12 \\
\hline Pen-I & $0.12-16.0$ & 1.0 & 8.0 \\
\hline \multicolumn{4}{|l|}{ Cefotaxime } \\
\hline Pen-S & $\leq 0.007-0.03$ & $\leq 0.007$ & 0.01 \\
\hline Pen-I & $\leq 0.007-1.0$ & 0.06 & 0.50 \\
\hline \multicolumn{4}{|l|}{ Ceftriaxone } \\
\hline Pen-S & $\leq 0.007-0.01$ & $\leq 0.007$ & $\leq 0.007$ \\
\hline Pen-I & $\leq 0.007-0.50$ & 0.06 & 0.25 \\
\hline \multicolumn{4}{|l|}{ Ceftazidime } \\
\hline Pen-S & $0.03-0.50$ & 0.12 & 0.25 \\
\hline Pen-I & $0.06-8.0$ & 2.0 & 8.0 \\
\hline \multicolumn{4}{|l|}{ Vancomycin } \\
\hline Pen-S & $0.25-0.50$ & 0.25 & 0.50 \\
\hline Pen-I & $0.25-0.50$ & 0.25 & 0.25 \\
\hline \multicolumn{4}{|l|}{ Teicoplanin } \\
\hline Pen-S & $\leq 0.007$ & $\leq 0.007$ & $\leq 0.007$ \\
\hline Pen-I & $\leq 0.007$ & $\leq 0.007$ & $\leq 0.007$ \\
\hline
\end{tabular}

MIC Minimal inhibitory concentration; Pen-S Penicillin susceptible; Pen-I Penicillin intermediate

In this study, we demonstrated that activity of the cephalosporins decreased with increasing penicillin mics. The mechanism of cephalosporin resistance was elucidated by Figueiredo et al (16) using a clinical isolate of $S$ pneumoniae (serotype 23F) that had high MICs to the third-generation cephalosporins cefotaxime and ceftriaxone ( $2.5 \mathrm{mg} / \mathrm{L}$ each). They discovered that this isolate had a pattern of penicillinbinding proteins (PBP) and a cell wall peptide composition that were different from those of penicillin-resistant pneumococci that were still susceptible to third-generation cephalosporins. Moreover, Muñoz et al (17) showed that third-generation cephalosporin resistance involved only alterations of $\mathrm{PBP} 2 \mathrm{X}$ and $\mathrm{PBP} 1 \mathrm{~A}$. This resistance could be readily transferred into a susceptible strain with only a single round of transformation.

Therapy for infections caused by cephalosporin-resistant $S$ pneumoniae strains poses a difficult problem. Friedland et al (18) assessed different antimicrobial regimens in a conventional animal model of meningitis caused by one of two cephalosporin-resistant $S$ pneumoniae strains - one strain was more resistant, with a ceftriaxone MIC of $4 \mathrm{mg} / \mathrm{L}$, and the other strain had a lower MIC to ceftriaxone of $1 \mathrm{mg} / \mathrm{L}$. They as- 
certained that ceftriaxone therapy lacked bactericidal activity in meningitis induced with the more resistant strain (ceftriaxone MIC $4 \mathrm{mg} / \mathrm{L}$ ). In addition, ceftriaxone in combination with vancomycin was found to be synergistic and was superior to vancomycin or ceftriaxone alone.

Teicoplanin is a glycopeptide antibiotic with a structure related to that of vancomycin (19). It is active against many Gram-positive bacteria such as staphylococci (including methicillin-resistant strains), streptococci, enterococci and many anaerobic Gram-positive bacteria. It has an exceptionally long half-life, permitting once-daily intramuscular or intravenous administration. It has been used successfully in patients with lower respiratory infections and bacteremias (19). Teicoplanin does not attain high concentration in the CSF with intravenous administration (19). In this study, teicoplanin was uniformly active against both pneumococcal strains that were penicillin-susceptible and those that were penicillinintermediate. Our results confirmed the good activity of teicoplanin reported in other studies $(20,21)$.

The prevalence of penicillin- and cephalosporin-resistant strains of $S$ pneumoniae is low but increasing. Our study demonstrates that penicillin resistance is a marker for cephalosporin resistance. We suggest that isolates demonstrating intermediate susceptibility or resistance to penicillin should be routinely evaluated for susceptibility to clinically important cephalosporins. This should be performed by broth microdilution or agar dilution since disk testing of $S$ pneumoniae with cefotaxime and ceftriaxone have been shown not to be reliable (22). In areas with high rates of pneumococcal resistance to extended spectrum cephalosporins, empirical therapy with vancomycin and a third-generation cephalosporin should be considered until the results of culture and susceptibility testing are available. Teicoplanin may also be used in nonmeningeal cases $(19,23)$. We advocate heightened awareness and continued monitoring of evolving resistance patterns for both penicillin and third-generation cephalosporins.

\section{REFERENCES}

1. Appelbaum PC. Antimicrobial resistance in Streptococcus pneumoniae: An overview. Clin Infect Dis 1992;15:77-83.

2. Fenoll A, Martín Bourgon C, Muñóz R, Vicioso D, Casal J. Serotype distribution and antimicrobial resistance of Streptococcus pneumoniae isolates causing systemic infections in Spain, 1979-1989. Rev Infect Dis 1991;13:56-60.

3. Thornsberry C, Marler JK, Rich TJ. Increased penicillin (pen) resistance in recent US isolates of Streptococcus pneumoniae. Program and Abstracts of the Ninety-second Annual Meeting of the American Society of Microbiology, New Orleans, 1992. (Abst C268)

4. Dixon JMS, Lipinski AE, Graham MEP. Detection and prevalence of pneumococci with increased resistance to penicillin. Can Med Assoc J 1977;117:1159-61.

5. Jetté LP, Lamothe F, and the Pneumococcus Study Group. Surveillance of invasive Streptococcus pneumoniae infection in Quebec, Canada, from 1984 to 1986: Serotype distribution, antimicrobial susceptibility and clinical characteristics. J Clin Microbiol 1989;27:1-5
6. Loo VG, Lavallée J, McAlear D, Robson HG. In-vitro susceptibility of Streptococcus pneumoniae to 9 antimicrobial agents, including penicillin, cefixime and newer quinolones. $J$ Antimicrob Chemother 1994;33:641-5.

7. Lapointe JR, Joncas JH. Meningitis in a Canadian infant due to pneumococcus resistant to penicillin and chloramphenicol. J Pediatr 1983;103:580-3.

8. Cherubin CE, Eng RHK, Norrby R, Modai J, Humbert G, Overturf G. Penetration of newer cephalosporins into cerebrospinal fluid. Rev Infect Dis 1989;11:526-48.

9. McCracken GH Jr, Nelson JD, Kaplan SL, Overtuff GD, Rodriguez WJ, Steele RW. Consensus report: Antimicrobial therapy for bacterial meningitis in infants and children. Pediatr Infect Dis J 1987;6:501-5.

10. Bradley JS, Connor JD. Ceftriaxone failure in meningitis caused by Streptococcus pneumoniae with reduced susceptibility to beta-lactam antibiotics. Pediatr Infect

Dis J 1991;10:871-3.

11. Sloas MM, Barrett FF, Chesney PJ, et al. Cephalosporin treatment failure in penicillin and cephalosporin-resistant Streptococcus pneumoniae meningitis. Pediatr Infect Dis J 1992;11:662-6.

12. Drug-resistant Streptococcus pneumoniae - Kentucky and Tennessee. MMWR 1993;43:23-5.

13. Marton A, Gulyas M, Munoz R, Tomasz A. Extremely high incidence of antibiotic resistance in clinical isolates of Streptococcus pneumoniae in Hungary. J Infect Dis 1991;163:542-8.

14. Facklam RR, Washington JA III. Streptococcus and related catalase negative Gram positive cocci. In: Balows A, Hausler WJ Jr, Herrmann KL, Isenberg HD, Shadomy HJ, eds. Manual of Clinical Microbiology, 5th edn. Washington, DC: American Society for Microbiology, 1991:238-57.

15. National Committee for Clinical Laboratory Standards. Methods for Dilution Antimicrobial Susceptibility Tests for Bacteria that Grow Aerobically. Approved Standard M7-A3. Villanova: National Committee for Clinical Laboratory Standards, 1993.

16. Figueiredo AMS, Connor JD, Severin A, Vaz Pato MV, Tomasz A. A pneumococcal clinical isolate with high-level resistance to cefotaxime and ceftriaxone. Antimicrob Agents Chemother 1992;36:886-9.

17. Muñoz R, Dowson CG, Daniels M, et al. Genetics of resistance to third-generation cephalosporins in clinical isolates of Streptococcus pneumoniae. Mol Microbiol 1992;6:2461-5.

18. Friedland IR, Paris M, Ehrett S, Hickey S, Olsen K, McCracken $\mathrm{GH} \mathrm{Jr}$. Evaluation of antimicrobial regimens for treatment of experimental penicillin- and cephalosporin-resistant pneumococcal meningitis. Antimicrob Agents Chemother 1993;37:1630-6.

19. Campoli-Richards DM, Brogden RN, Faulds D. Teicoplanin: A review of its antibacterial activity, pharmacokinetic properties and therapeutic potential. Drugs 1990;40:449-86.

20. Appelbaum PC, Spangler SK, Crotty E, Jacobs MR. Susceptibility of penicillin-sensitive and -resistant strains of Streptococcus pneumoniae to new antimicrobial agents including daptomycin, teicoplanin, cefpodoxime and quinolones. J Antimicrob Chemother 1989;23:509-16.

21. Florez C, Perez MJ, Aretio R, Parras P, Martin E. Susceptibility of Streptococcus pneumoniae to five antibiotics. J Antimicrob Chemother 1992;30:727-8.

22. National Committee for Clinical Laboratory Standards. Performance Standards for Antimicrobial Disk Susceptibility Tests, 5th edn. Approved Standard M2-A5. Villanova: National Committee for Clinical Laboratory Standards, 1993.

23. Stille W, Sietzen W, Dieterich HA, Fell JJ. Clinical efficacy and safety of teicoplanin. J Antimicrob Chemother 1988;21(Suppl A):69-79. 


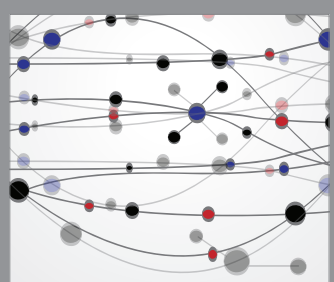

The Scientific World Journal
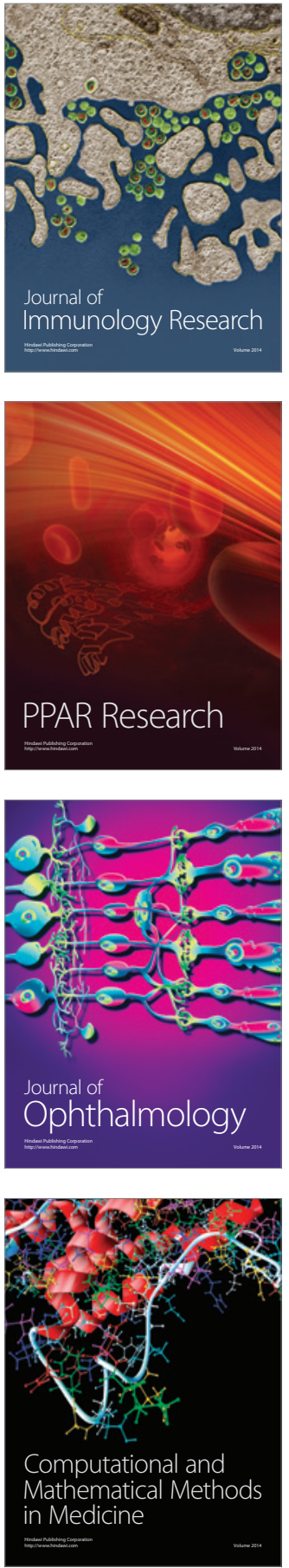

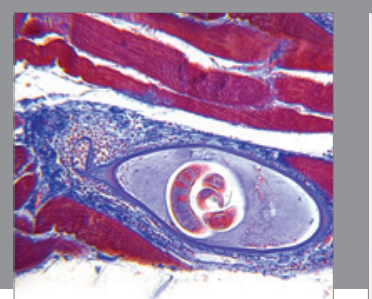

Gastroenterology Research and Practice

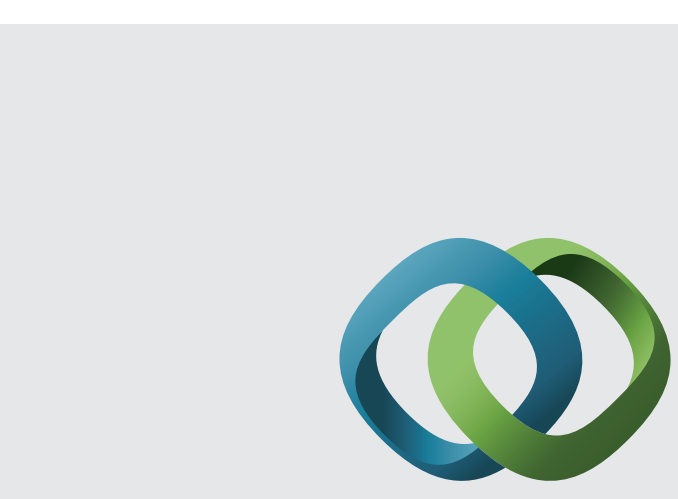

\section{Hindawi}

Submit your manuscripts at

http://www.hindawi.com
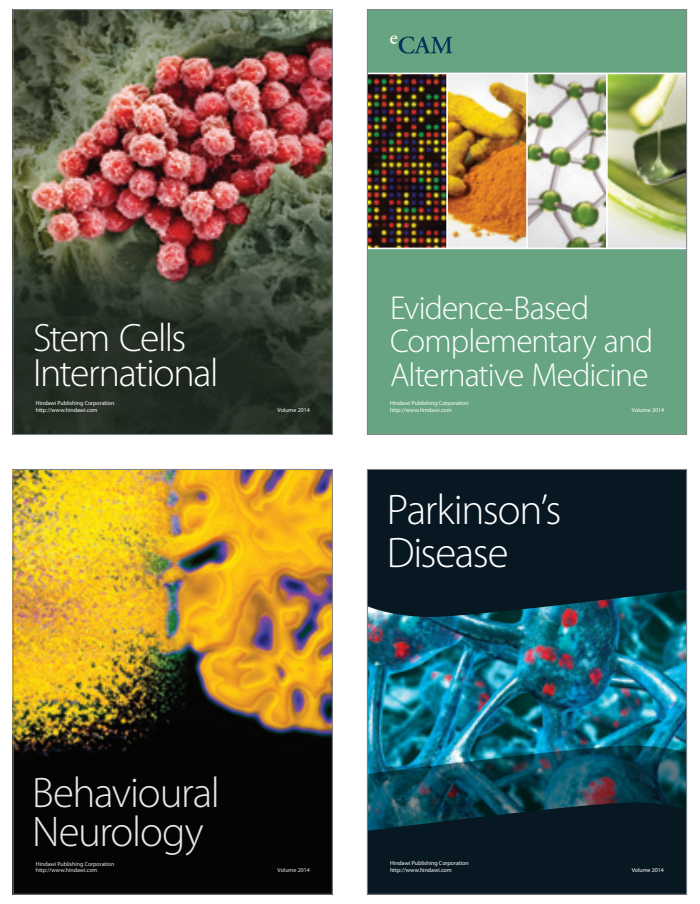
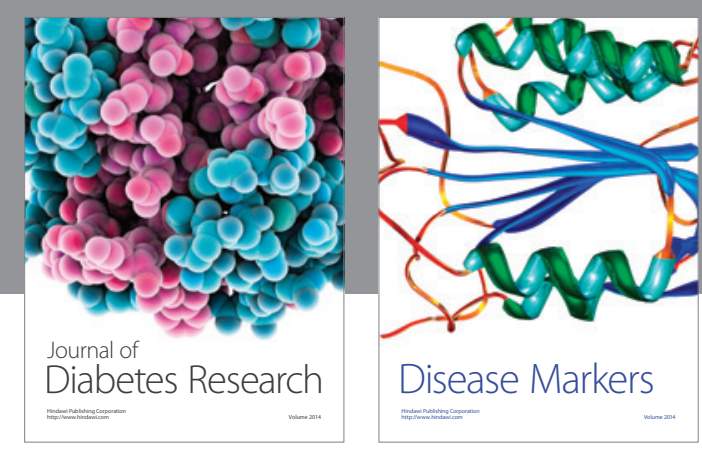

Disease Markers
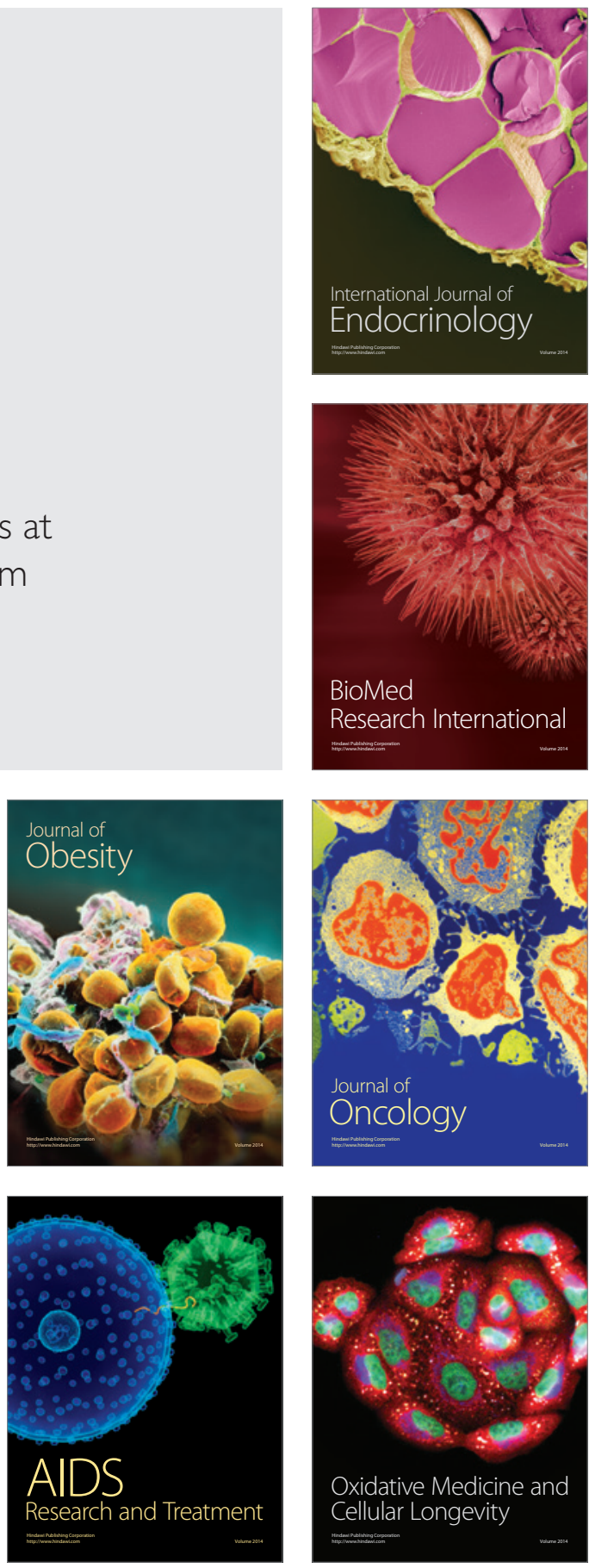